\title{
Music As an Alternative Therapy Method in Dentistry
}

\author{
Milica Jovanović-Medojević', Jelena Nešković1, Aleksandar Medojević \\ ${ }^{1}$ University of Belgrade, Faculty of Dental Medicine, Department of Restorative Dentistry and Endodontics, Belgrad, Serbia; \\ ${ }^{2}$ Institute for Health Protection of Employees at the Ministry of Internal Affairs, Belgrade, Serbia
}

\begin{abstract}
SUMMARY
Dental fear represents a significant social concern. Therefore, an individual approach to each patient and timely recognition and elimination of dental stress are necessary in order to provide adequate and successful treatment. The aim of this paper was to present possible application of music therapy in dentistry and its role in reducing dental fear. Music has shown great prospective as an alternative therapy method in various fields of medicine. Music therapy is painless and noninvasive anxiolytic method that reduces dental anxiety as it provides relaxation and distraction. Music in dental office creates positive atmosphere among patients and their company as well as dental staff.
\end{abstract}

Keywords: dental fear; music therapy; dental office

\section{INTRODUCTION}

Music is omnipresent in human culture and has been deeply woven into the fabric of everyday life regardless of race, age, social and economic status and ethnic origin. Music helps expressing personal feelings and establish contacts with other people. Importance of music and its positive effect on health originates from centuries before Christ, which has been documented in ancient papers of Chinese medicine and Indian Samaveda [1,2]. Pythagoras, the sixth-century Greek philosopher who is considered as founder of music therapy, believed that music has an overall positive influence on body as well as on psyche creating a unique harmony between them [3]. In the past years, music therapy has become more popular and has been applied during various medical procedures (surgical interventions, intensive care, cancer treatment, psychiatry, cardiology, therapy of pre-operative anxiety) [4].

Fear of dental procedures is still a significant social problem. Therefore, an individual approach to each patient and timely recognition and elimination of dental stress are necessary in order to provide adequate and successful treatment. Diseases, injuries, hospitalization and dental treatments are often stressful and as such, they can have negative influence on cardiovascular, neuroendocrine and immune system. They can impede recovery or trigger complications. [5,6]. Prevalence of dental anxiety is estimated at $6-15 \%$ of the world's adult population, and in children the prevalence ranges between $5.7 \%$ and $19.5 \%$ [7]. Anxious patient does not fully cooperate with dental practitioner. Such situation prolongs the procedure and makes it more difficult. As a result, elimination of patient's anxiety may improve the quality, effectiveness and success of dental treatment - and hence improve overall health of patients [1]. It is proved that anxious patients need $20 \%$ more time for dental treatment compared to patients who cooperate adequately (probably because of frequent interruptions during the treatment) [8]. It has also been shown that patients with severe dental fear, in the months after the dental treatment, have increased prevalence of flu and cold [9].

The aim of this article was to present possible application of music therapy in dentistry and its role in reducing dental fear.

\section{MUSIC THERAPY}

Music is an art form with main elements: pitch, rhythm, dynamics and sound characteristics such as timbre and resonance. Application of music for anxiety reduction is usually called music relaxation, audio-analgesia or audio anxiolysis [10]. Music with relaxation effect is usually called anxiolytic music and most often includes compositions characterized by slow tempo, repetitive rhythmic patterns, predictable dynamics and constant harmony $[11,12]$.

Music can influence emotions, intellect and psyche. Music therapy can be active or passive. Active music therapy (per Munro and Mount) includes controlled use of music in order to achieve psychological, physiological and emotional integrity during treatment [13]. This therapy is performed by specially trained musicians, professional music therapists who work in hospitals, clinics, schools, rehabilitation centers and who use various music techniques (listening, singing, playing instruments, composing music and moving with music) [4]. Passive music therapy is passive listening to pre-recorded music without direct involvement of music therapist.

Some studies indicate that active music therapy in medicine is significantly more effective than passive music listening $[14,15]$. This difference can be attributed to the fact that active music therapy individualizes its intervention to meet patient's specific needs. [14]. Cook [16] 
in her paper stated that dentists were one of the leading proponents of music therapy, using it to promote relaxation and pain control for their patients. Passive music listening which has audio-analgesic, anxiolytic or sedation effects may be applied independently or with pharmacological (anesthesia and analgesia) or non-pharmacological therapy (suggestion, relaxation techniques, hypnosis, acupuncture, meditation,...) [17].

\section{THERAPEUTIC EFFECTS OF MUSIC}

Music has overall positive influence on body and psyche since it stimulates emotions, motivates, renews memories and soothes [18]. Music increases the level of creativity and optimism, contributes to positive feelings and prevents depression and anxiety. The importance of sense of hearing is confirmed by the fact that it is developed before the sense of sight in embryonic stage and it is the first functional sense in human life [4]. Sound is not limited by time and space; therefore, in the form of impulse, it reaches nervous system easily and influences brain waves changing physiological and psychological condition of an individual [19]. Music easily reaches all parts of brain and activates them by creating new and more complex connections and bypassing damages in the existing cell connections. Music uses rhythm to change neural activity in lateral temporal lobe and cortical area that control movements and triggers expression of opioid receptor morphine-6-glucuronide and interleukin 6 [5]. In addition, other significant effects of music therapy are increased level of excreted immunoglobulin and decreased serum cortisol level [20].

It is well-known that certain music can have positive influence on concentration, patience and significantly reduce anxiety [21]. Such changes in brain activity under the influence of music overcome certain problems, even when the music stops. In addition, music has an impact on autonomous nervous system (heart rate and breathing), since it reduces blood pressure, increases immunity, decreases muscle tension and pain intensity. Studies of music therapists show that music with pronounced rhythm stimulates brain waves to adopt the same rhythm. When the rhythm gets faster, pulse and breathing get increased as well. This improves concentration and makes thinking process faster which can be used to improve physical performance. Slow music rhythm sooths and relaxes resulting in slower breathing and decreased heart rate and overall relaxation [4]. Simultaneously, music influences physiological and psychological condition of an individual [22]. It has been shown that listening to music for therapeutic anxiolytic purposes leads to changes in automatic and central nervous system causing positive physiological reactions of patients [23].

Music theorists Bonny, Gfeller and Guzzetta state that music has the ability to distract and divert attention away from stressful stimuli and promote feelings of physical and mental relaxation by refocusing attention on pleasurable emotional state and blocking unpleasant environmental sounds [4].

\section{MUSIC AND DENTAL ANXIETY}

Dental anxiety is often caused by unpleasant sounds in dental office, but music can mask such sounds and have direct influence on pain reduction [17, 24]. Music can, with the use of auditory distractions and activation of large number of neurotransmitters, divert attention and eliminate feelings of pain and fear [25]. Many factors cause anxiety and fear in dental office, but sense of loosing control due to unfamiliar situation and environment is definitely one of the most significant factors [26]. Listening to familiar and preferred music also helps patients to regain sense of control [27]. It is believed that pain control may block paths to brain receptors by music and as a result reduce pain perception and necessary doses of analgesics [28, 29]. Such application of music is often called white noise effect, and it implies playing the music before the procedure starts.

Effect of music on patients during various medical procedures has been studied from various aspects [30]. Anxiety especially relates to patients that undergo painful and stressful medical and dental procedures [31]. Anxiolytic effects of music have been studied for the last 20 years during different medical treatments (surgical, cardiac, oncologic and other patients) $[4,31,32]$.

In 1981, Parkin [33] studied the effect of music on reducing anxiety level among children by playing 5-minute ambience music prior to dental treatment. Students who listened to music in stressful situations marked lower levels of excreted cortisol, while students who did not listen to music marked significantly higher levels [33]. In 2005, Cooke et al. [34] reported relaxing effect of music by focusing mental and physical attention toward some other pleasant emotional state. Some researchers indicated that soothing music leads to relaxation and attention distraction, which reduces neuroendocrine activity and sympathetic nervous system resulting in decrease of fear, heart and respiratory rate, blood pressure [30,35]. According to the studies of Olszewska and Žarow [21], patients who were listening to music during dental treatment showed: lower level of tension, better approachability and adjustment to all types of treatments. Music had a positive influence on fear and comfort during intervention, especially among patients with moderate and high level of anxiety, regardless of patient's sex and age [21]. Tran et al. [36] conducted a survey in 2010 among patients and dental professionals on preferred anxiolytic interventions during dental treatment. It has been confirmed that $89 \%$ of patients and dental professionals prefer listening to ambient music during dental interventions.

However, efficient application of music during dental treatment may be compromised by the use of inadequate music [30]. Therefore, it is necessary and very important that patients listen to familiar and preferred music during medical procedure (if possible, a patient should choose music) [30]. Researchers also indicate that music genre used to achieve a desirable effect differs since it is a unique experience for each person and depends on many factors: sex, age, attitudes, culture, personal traits or current mood $[17,37]$. Intensive stimulation by excessively 
loud sounds might even aggravate pain while extremely soft sound might increase anxiety [37].

Despite large number of studies on the effect of music during various medical treatments, research related to the application of music during dental treatments is still vague [38]. Different results are usually consequence of various studies and individual factors such as music taste, age, sex, patient's culture etc. Therefore, individual characteristics such as health condition, level of awareness, pain tolerance and personality itself, environment, musical knowledge and previous music experience, have the most important role in the effectiveness of music during various therapy procedures.

\section{CONCLUSION}

Music has significant positive potential as an alternative therapy method in various fields of medicine. Music therapy is painless and noninvasive anxiolytic method and when compared to pharmacological and other treatments it does not require great investments in training or equipment. Music significantly reduces dental anxiety with its soothing or distracting effects. Therefore, music therapy is cheap, easily accessible and not demanding anxiolytic method for everyday dental practice. Music in waiting rooms and dental offices creates positive atmosphere for patients, their company and dental professionals.

\section{REFERENCES}

1. Chiu WSI. Effect of music on anxiety management during dental procedures [Master Thesis]. Hong Kong: University of Hong Kong; 2010.

2. Katz JB. Music therapy: some possibilities in the indian tradition. In: Horden P, editor. Music as Medicine: The History of Music Therapy Since Antiquity. Aldershot, Brookfield, VT.: Ashgate; 2000. p.84-102.

3. White JM. Music as intervention: a notable endeavor to improve patient outcomes. Nurs Clin North Am. 2001; 36:83-92. [PMID: 11342404]

4. Moola S, Pearson A, Hagger C. Effectiveness of music interventions on dental anxiety in pediatric and adult patients: a systematic review. JBI Library System Rev. 2011; 9:588-630.

5. Kemper KJ, Danhauer SC. Music as therapy. South Med J. 2005; 98:282-8. [DOI: 10.1097/01.SMJ.0000154773.11986.39] [PMID: 15813154]

6. Biondi M, Zannino LG. Psychological stress, neuroimmunomodulation, and susceptibility to infectious diseases in animals and man: a review. Psychother Psychosom. 1997; 66:3-26.

[DOI: 10.1159/000289101] [PMID: 8996711]

7. The Joanna Briggs Institute. Music interventions for dental anxiety in pediatric and adult patients. Best Practice. 2011; 15:1-4.

8. Filewich RJ, Jackson E, Shore H. Effects of dental fear on efficiency of routine dental procedures. J Dent Res. 1981; 60:533.

9. Logan HL, Lutgendorf S, Kirchner HL, Rivera EM, Lubaroff D. Pain and immunologic response to root canal treatment and subsequent health outcomes. Psychosom Med. 2001; 63:453-62. [PMID: 11382273]

10. Stuhlmiller DF, Lamba S, Rooney M, Chait S, Dolan B. Music reduces patient anxiety during interfacility ground critical care transport. Air Med J. 2009; 28:88-91. [DOI: 10.1016/j.amj.2008.10.008] [PMID: 19272573]

11. McClellan R. The Healing Forces of Music: History, Theory and Practice. Rockport, Mass: Element; 1991.
12. Watkins GR. Music therapy: proposed physiological mechanisms and clinical implication. Clin Nurse Spec. 1997; 11:43-50. [PMID: 9233140]

13. Munro S, Mount B. Music therapy in palliative care. Can Med Assoc J. 1978; 119:1029-34. [PMID: 84704 ]

14. Dileo CD, Bradt J. Medical Music Therapy: A Meta-analysis and Agenda for Future Research. Cherry Hill, NJ: Jeffrey Books; 2005.

15. Goff LC, Pratt RR, Madrigal JL. Music listening and S-IgA levels in patients undergoing a dental procedure. Int J Arts Med. 1997; 5:22-6.

16. Cook J. The therapeutic use of music: a literature review. Nurs Forum. 1981; 20:252-66. [PMID: 6926532]

17. Standley JM. A meta-analysis on the effects of music as reinforcement for education/therapy objectives. I Res Music Educ. 1996; 44:105-33. [DOl: $10.2307 / 3345665$ ]

18. Lahmann C, Schoen R, Henningsen P, Ronel J, Muehlbacher M, Loew $T$, et al. Brief relaxation versus music distraction in the treatment of dental anxiety: a randomised controlled clinical trial. J Am Dent Assoc. 2008; 139:317-24. [DOI: 10.14219/jada.archive.2008.0161] [PMID: 18310736]

19. Klingberg G, Broberg AG. Dental fear/anxiety and dental behaviour management problems in children and adolescents: a review of prevalence and concomitant psychological factors. Int J Paediatr Dent. 2007; 17:391-406. [DOI: 10.1111/j.1365-263X.2007.00872.x] [PMID: 17935593]

20. Urakawa K, Yokoyama K. Can relaxation programs with music enhance human immune function? ) Altern Complement Med. 2004; 10:605-6. [DOI: 10.1089/1075553041829334] [PMID: 15353014]

21. Olszewska I, Żarow M. Does music during dental treatment make a difference? J Dent Res. 2003; 82:B-351. Available from: http://www. silenceofmusic.com/pdf/dentists.pdf.

22. Sendelbach SE, Halm MA, Doran KA, Miller EH, Gaillard PJ. Effects of music therapy on physiological and psychological outcomes for patients undergoing cardiac surgery. J Cardiovasc Nurs. 2006; 21:194200. [PMID: 16699359]

23. Wigram T, Pederson IN, Bonde LO. A Comprehensive Guide to Music Therapy. London: Jessica Kingsley; 2002.

24. Rankin JA, Harris MB. Patients' preferences for dentists' behaviors. Am Dent Assoc. 1985; 110:323-7. [DOI: 10.14219/jada.archive.1985.0349] [PMID: 3858344$]$

25. Thaut $\mathrm{MH}$. The future of music in therapy and medicine. Ann N Y Acad Sci. 2005; 1060:303-8. [DOI: 10.1196/annals.1360.023] [PMID: 16597779]

26. Gillen E, Biley F, Allen D. Effects of music listening on adult patients' pre-procedural state anxiety in hospital. Int J Evid Based Healthc. 2008; 6:24-49. [DOI: 10.1111/j.1744-1609.2007.00097.x] [PMID: 21631813]

27. Davis W, Gfeller K, Thaut M. An Introduction to Music Therapy: Theory and Practice. Dubuque, IA: Wm. C. Brown Publishers; 1992.

28. Megel ME, Houser CW, Gleaves LS. Children's responses to immunizations: lullabies as a distraction. Issues Compr Pediatr Nurs. 1998; 21:129-45. [PMID: 10531890]

29. Lee OKA, Chung YFL, Chan MF, Chan WM. The effect of music on the physiological responses and anxiety levels of patients receiving mechanical ventilation: a pilot study. J Clin Nurs. 2005; 14:609-20. [DOI: 10.1111/j.1365-2702.2004.01103.x] [PMID: 15840076]

30. Lai HL, Good M. The overview of music therapy. The Journal of Nursing. 2002; 49:80-4.

31. Mitchell M. Patient anxiety and modern elective surgery: a literature review. J Clin Nurs. 2003; 12:806-15. [DOI: 10.1046/j.1365-2702.2003.00812.x] [PMID: 14632973]

32. Lai HL, Hwang MJ, Chen C), Chang KF, Peng TC, Chang FM. Randomised controlled trial of music on state anxiety and physiological indices in patients undergoing root canal treatment. J Clin Nurs. 2008; 17:2654-60. [DOI: 10.1111/j.1365-2702.2008.02350.x] [PMID: 18808630]

33. Parkin SF. The effect of ambient music upon the reactions of children undergoing dental treatment. ASDC J Dent Child. 1981; 48:430-2. [PMID: 6946085]

34. Cooke M, Chaboyer W, Schluter P, Hiratos M. The effect of music on preoperative anxiety in day surgery. J Adv Nurs. 2005; 52:47-55. [DOI: 10.1111/j.1365-2648.2005.03563.x] [PMID: 16149980] 
35. Hartley NA. On a personal note: a music therapist's reflections on working with those who are living with a terminal illness. J Palliat Care. 2001; 17:135-41. [PMID: 11816752]

36. Tran D, Edenfield SM, Coulton K, Adams D. Anxiolytic intervention preference of dental practitioners in the savannah, chatham county area: a pilot study. J Dent Hyg. 2010; 84:151-5. [PMID: 20579428]
37. Gfeller KE, Logan H, Walker J. The effect of auditory distraction and suggestion on tolerance for dental restoration in adolescents and young adults. I Music Ther. 1990; 27:13-23. [DOl: 10.1093/jmt/27.1.13]

38. Armfield J M, Heaton LJ. Management of fear and anxiety in dental clinic: a review. Aust Dent J. 2013; 58:390-407.

[DOl: 10.1111/adj.12118] [PMID: 24320894]

Received: 20/10/2015 • Accepted: 08/02/2016 


\title{
Muzika kao alternativna terapijska metoda u stomatologiji
}

\author{
Milica Jovanović-Medojević', Jelena Nešković1, Aleksandar Medojević \\ 'Univerzitet u Beogradu, Stomatološki fakultet, Klinika za bolesti zuba i endodonciju, Beograd, Srbija; \\ ${ }^{2} Z a v o d$ za zaštitu zdravlja radnika MUP-a, Beograd, Srbija
}

\begin{abstract}
KRATAK SADRŽAJ
Strah od stomatološke intervencije je i danas značajan društveni problem, pa su zato neophodni individualni pristup svakom pacijentu i pravovremeno prepoznavanje i eliminacija dentalnog stresa, kako bi se realizovala odgovarajuća i uspešna terapija. Cilj ovog rada je bio da ukaže na mogućnosti primene muzikoterapije u stomatologiji i predstavi njene efekte u eliminaciji dentalne anksioznosti. Muzika ima značajan pozitivan potencijal kao alternativna terapijska metoda u raznim poljima medicine. Muzikoterapija je bezbolna i neinvazivna anksiolitička metoda koja smanjuje dentalnu uznemirenost svojim opuštajućim ili efektom skretanja pažnje. Muzika u stomatološkoj ordinaciji stvara pozitivnu atmosferu pacijentima, njihovoj pratnji, ali i stručnom osoblju.

Ključne reči: dentalni strah; muzikoterapija; stomatološka ordinacija
\end{abstract}

\section{UVOD}

Muzika je sveprisutna u ljudskoj kulturi i od davnina je duboko utkana u svakodnevni život, bez obzira na rasu, godine, socioekonomski status i etničko poreklo. Muzika pomaže u izražavanju sopstvenih osećanja i ostvarivanja kontakata sa drugim ljudima. Verovanja u značaj muzike i njen povoljan uticaj na zdravlje potiču vekovima pre nove ere, što je dokumentovano u spisima o staroj kineskoj medicini i u drevnoj indijskoj Samaveda knjizi $[1,2]$. Pitagora, grčki filozof iz šestog veka, koji se smatra ocem muzikoterapije, verovao je da muzika ima sveobuhvatan pozitivan uticaj kako na telo, tako i na psihu, stvarajući pri tome jedinstvenu harmoniju [3]. Poslednjih godina terapija muzikom postaje sve popularnija i primenjuje se u različitim medicinskim procedurama (operacije, intenzivna nega, terapija raka, psihijatrija, kardiologija, terapija preoperacione anksioznost itd.) [4].

Strah od stomatološke intervencije je i danas značajan društveni problem, pa su zato neophodni individualni pristup svakom pacijentu i pravovremeno prepoznavanje i eliminacija dentalnog stresa, kako bi se realizovala odgovarajuća i uspešna terapija. Bolest, povrede, hospitalizacija i stomatološko lečenje su vrlo često stresogeni, što može nepovoljno uticati na kardiovaskularni, neuroendokrini i imunski sistem, te time oslabiti oporavak bolesnika, odnosno pospešiti pojavu komplikacija [5, 6]. Procenjuje se da se dentalna anksioznost javlja kod 6-15\% odraslih osoba u svetu, dok je kod dece u rasponu od 5,7\% do 19,5\% [7]. Uznemireni pacijent ne sarađuje potpuno sa stomatologom, čime se produžava vreme i otežava izvođenje dentalne procedure, pa eliminacija uznemirenosti stomatoloških pacijenata poboljšava kvalitet, efikasnost i uspeh stomatološkog lečenja, utičući time na pacijentovo opšte zdravlje [1]. Utvrđeno je da anksiozni pacijenti zahtevaju oko $20 \%$ više vremena za stomatološki tretman u odnosu na pacijente koji adekvatno sarađuju (verovatno zbog češćih prekida tokom rada) [8]. Dokazano je takođe da pacijenti s težim stepenom dentalnog straha u mesecima koji slede posle stomatološkog lečenja imaju povećanu prevalenciju gripa i prehlade [9].

Cilj ovog rada bio je da ukaže na mogućnosti primene muzikoterapije u stomatologiji i predstavi njene efekte u eliminaciji dentalne anksioznosti.

\section{MUZIKOTERAPIJA}

Muzika je umetnost čiji su osnovni elementi ton, ritam, dinamika i osobine zvuka kao što su boja i punoća. Primena muzike za ublažavanje anksioznosti se najčešće naziva „opuštanje uz muziku“,,,audio-analgezija“ “ili „audio-anksioliza“ [10]. Muzika s opuštajućim efektom se naziva anksiolitička i najčešće obuhvata kompozicije sporog tempa, ponavljajućeg ritma, predvidljive dinamike i konsonantne harmonije $[11,12]$.

Muzika može uticati na emocije, intelekt i psihu, a ova terapija može biti aktivna ili pasivna. Aktivna terapija muzikom, po Munrou (Munro) i Mauntu (Mount), podrazumeva kontrolisano korišćenje muzike kako bi se postigao psihološki, fiziološki i emocionalni integritet tokom tretmana [13]. Ovu terapiju izvode specijalno obučeni muzičari, profesionalni muzikoterapeuti, koji rade u bolnicama, klinikama, školama, rehabilitacionim centrima i koriste razne muzičke tehnike (slušanje, pevanje, sviranje, stvaranje muzike i kretnje uz muziku) [4]. Pasivna terapija muzikom podrazumeva pasivno slušanje ranije snimljene muzike od strane terapeuta i bez učešća muzikoterapeuta.

Neka istraživanja pokazuju da aktivna muzička terapija u medicini ima statistički značajno više dejstva od intervencije uz pasivno slušanje muzike $[14,15]$. Razlika može biti uzrokovana činjenicom da aktivna muzikoterapija individualizuje intervenciju sa specifičnim pacijentovim potrebama [14]. Kuk (Cook) [16] u svom radu navodi da su stomatolozi izraziti zagovornici muzikoterapije za relaksaciju i kontrolu bola pacijenata. Pasivno slušanje muzike u funkciji audio-analgetika, anksiolitika ili sedativa može se primenjivati samostalno ili uz farmakološku, (anestezija i analgezija) ili nefarmakološku terapiju (sugestija, relaksacione tehnike, hipnoza, akupunktura, meditacija) [17].

\section{TERAPIJSKI EFEKTI MUZIKE}

Muzika ima sveobuhvatan pozitivan uticaj na telo i psihu, jer podstiče emocije, motiviše, obnavlja sećanja i smiruje [18]. Muzika podiže nivo kreativnosti i optimizma, doprinosi pozitivnim osećanjima i tako štiti od depresije ili anksioznosti. Značaj sluha se potvrđuje u činjenici da se razvija pre vida u embrionalnom stadijumu, i to je prvo funkcionalno čulo u životu čoveka [4]. Za zvuk ne postoje ograničenja u vremenu i granice u prostoru, te vrlo lako u formi impulsa dolazi do nervnog sistema i utiče na 
moždane talase menjajući fiziološko i psihološko stanje pojedinca [19]. Muzika lako dolazi do svih delova mozga i aktivira ih stvarajući nove i složenije veze, odnosno premošćava oštećenja u već postojećim ćelijskim vezama. Ona svojim ritmom može menjati neuralnu aktivnost u lateralnom temporalnom režnju i u kortikalnoj oblasti zaduženoj za pokret, pri čemu dovodi do ekspresije opijate receptora morfin-6 glukuronida i interleukina 6 [5]. Pozitivne fiziološke promene, kao što je povećanje nivoa izlučenog imunoglobulina, odnosno smanjenje nivoa kortizola u serumu, takođe su značajni efekti muzikoterapije [20].

Poznato je da određena muzika može imati pozitivan uticaj na koncentraciju, strpljenje i značajno smanjenje uznemirenosti [21]. Ove promene moždane aktivnosti pod uticajem muzike olakšavaju savladavanje određenih problema čak i kada se završi slušanje muzike. Muzika utiče i na autonomni nervni sistem (na rad srca i disanje), jer smanjuje krvni pritisak, pojačava imunitet, smanjuje napetost mišića i doživljaj intenziteta bola. Istraživanja muzikoterapeuta pokazuju da muzika izraženog ritma stimuliše moždane talase da rezonuju u istom ritmu. Ubrzanjem ritma muzike ubrzavaju se i puls i disanje, te dolazi do pojačanja koncentracije i bržeg razmišljanja, što se može iskoristiti za poboljšanje učinka u fizičkoj aktivnosti. Sporiji muzički ritam relaksira i smiruje, a usporenjem disanja i smanjivanjem brzine rada srca dolazi do opuštanja [4]. Muzika istovremeno utiče i na fiziološko i na psihološko stanje pojedinca [22]. Dokazano je da slušanje muzike u terapijske anksiolitičke svrhe dovodi do promena u automatskom i centralnom nervnom sistemu, izazivajući pozitivne fiziološke reakcije pacijenata [23].

Teoretičari muzike Boni (Bonny), Gfeler (Gfeller) i Guzeta (Guzzetta) smatraju da muzika ima mogućnost skretanja pažnje sa stresnih stimulusa i da utiče na fizičku i mentalnu relaksaciju, fokusirajući se na prijatna emotivna stanja i blokirajući neprijatne zvukove u okolini [4].

\section{MUZIKA I DENTALNI STRES}

Dentalni strah je često uzrokovan neprijatnim zvucima u stomatološkoj ordinaciji, a upravo muzika može maskiranjem tog zvuka direktno uticati na smanjenje bola [17,24]. Muzika može auditivnim ometanjem i aktiviranjem velikog broja neurotransmitera dovesti do skretanja pažnje i eliminacije osećaja bola i straha [25]. Mnogo je faktora koji izazivaju napetost i strah u stomatološkoj ordinaciji, ali je osećaj gubitka kontrole zbog nepoznate situacije i okruženja sigurno jedan od najvažnijih [26]. Slušanje poznate ili željene muzike takođe pomaže pacijentima da povrate osećaj kontrole [27]. Smatra se da se kontrolom bola putevi prema receptorima u mozgu mogu blokirati muzikom i time smanjiti percepcija bola, ali i doze neophodnih analgetika $[28,29]$. Ovakva primena muzike se često naziva efektom „bele buke“, a podrazumeva uključenje muzike pacijentima obavezno pre početka tretmana.

Efekat muzike na pacijente tokom različitih medicinskih procedura je ispitivan s različitih aspekata [30]. Anksioznost se posebno odnosi na pacijente koji moraju da se podvrgnu bolnim i stresnim medicinskim i stomatološkim zahvatima [31]. Anksiolitički efekat muzike je proučavan poslednjih 20 godina u različitim studijama i kod različitih medicinskih tretmana (hirurških, kardioloških, onkoloških i drugih) [4, 31,32].
Parkin (Parkin) [33] je 1981. godine proučavao efekat muzike na smanjenje anksioznosti kod dece u vidu petominutnog slušanja ambijentalne muzike pre stomatološkog lečenja. Kod učenika koji su slušali muziku je u stresnim situacijama zapažen niži nivo izlučenog kortizola, dok je kod učenika koji nisu slušali muziku taj nivo bio znatno viši [33]. Kuk (Cooke) i saradnici [34] su 2005. godine dokazali opuštajući efekat muzike, zahvaljujući mentalnom i fizičkom preusmeravanju pažnje prema nekom ugodnom emotivnom stanju. Neki istraživači su pokazali da umirujuća muzika opušta i odvraća pažnju, čime smanjuje aktivnost neuroendokrinog i simpatičkog nervnog sistema, što dovodi do smanjenja straha, srčanog ritma, respiratornog ritma i krvnog pritiska [30,35]. Prema istraživanjima Olsevske (Olszewske) i Žarova (Žarow) [21], pacijenti koji su slušali muziku tokom stomatološkog zahvata su pokazali niži nivo tenzije, veću pristupačnost i bolju prilagodljivost svim vrstama tretmana. Muzika je pozitivno uticala na strah i komfor tokom intervencije, posebno kod pacijenata sa srednjim i visokim nivoom uznemirenosti, bez obzira na pol i starost pacijenta [21]. Tran (Tran) i saradnici [36] su 2010. godine sproveli anketu kod stomatološkog osoblja i pacijenata o prioritetnim anksiolitičkim intervencijama tokom dentalnog tretmana. Potvrđeno je da $89 \%$ pacijenata i stomatoloških stručnjaka više voli slušanje ambijentalne muzike tokom stomatološke intervencije.

Međutim, efikasnost primene muzike tokom dentalnog tretmana može biti narušena puštanjem neodgovarajuće muzike [30]. Zato je neophodno da pacijenti slušaju poznatu i poželjnu muziku tokom medicinske procedure (po mogućstvu da je sam pacijent izabere) [30]. Istraživači takođe pokazuju da se vrsta muzike koja se koristi za postizanje željenog efekta razlikuje od osobe do osobe, jer je ona jedinstveno iskustvo za svaku osobu i zavisi od mnogih faktora: pola, starosti, stavova, kulture, osobina ličnosti, trenutnog raspoloženja $[17,37]$. Intenzivna stimulacija upotrebom prekomerne jačine zvuka može čak da pogorša bol, dok previše mekan zvuk može pojačati uznemirenost [37].

Uprkos velikom broju istraživanja o uticaju muzike na različite medicinske tretmane, rezultati o njenom uticaju na dentalni tretman su i danas prilično nejasni [38]. Razlike u rezultatima su najčešće posledica različitih studija i individualnih faktora, kao što su muzičke sklonosti, starost, pol, kultura pacijenata itd. Dakle, individualne karakteristike, poput zdravstvenog stanja, nivoa budnosti, tolerancije bola i same ličnosti, životne sredine, poznavanja muzike i prethodnog muzičkog iskustva, imaju najvažniju ulogu u efektima muzike u različitim terapijskim procedurama.

\section{ZAKLJUČAK}

Muzika je značajan pozitivan potencijal kao alternativna terapijska metoda u raznim poljima medicine. Muzikoterapija je bezbolna i neinvazivna anksiolitička metoda i, za razliku od farmakoloških i drugih tretmana, ne zahteva velika ulaganja u obuku ili opremu. Muzika značajno smanjuje dentalnu uznemirenost svojim opuštajućim ili efektom skretanja pažnje. Muzikoterapija je, dakle, jeftina, lako dostupna i nezahtevna anksiolitička metoda za svakodnevnu stomatološku praksu. Muzika u čekaonicama i stomatološkoj ordinaciji stvara pozitivnu atmosferu pacijentima, njihovoj pratnji, ali i stručnom osoblju. 